\title{
Eagle syndrome: elongated stylohyoid-associated facial pain
}

\author{
Anand Goomany, Assem Shayah, Brook Adams, Andrew Coatesworth
}

York Teaching Hospital NHS Foundation Trust, York, UK

\section{Correspondence to Anand Goomany; anandg@doctors.org.uk}

Accepted 13 March 2020

\section{DESCRIPTION}

A 47-year-old man with a history of recent root canal treatment on a lower left molar, presented to the Maxillofacial Surgery Department with a 6-month history of left-sided facial pain. This was exacerbated by yawning and radiated to the angle of the mandible. Examination revealed a fullness posterior to the left angle of the mandible but no discrete mass. In light of his recent dental treatment, an orthopantomogram was obtained to exclude a dental cause for the symptoms. This demonstrated a small periapical pathology associated with the lower left molar, in keeping with recent treatment. The possibility of a calcified left stylohyoid ligament was raised; however, this was deemed to be likely artifactual. Parotid ultrasound was unremarkable.

Referral was subsequently made to the Otorhinolaryngology Department for further assessment. Here it was found that the patient's symptoms could be reproduced by digital palpation within the left tonsillar fossa. A CT scan of the neck demonstrated an enlarged left styloid process with calcification of the stylohyoid ligament, characteristic of Eagle syndrome (figures 1 and 2). The patient underwent a left neck exploration with styloidectomy. The specimen was $7.5 \mathrm{~cm}$ long and contained interrupted segments of the mineralised ligament (creating the appearance of multiple pseudoarticulations, a type

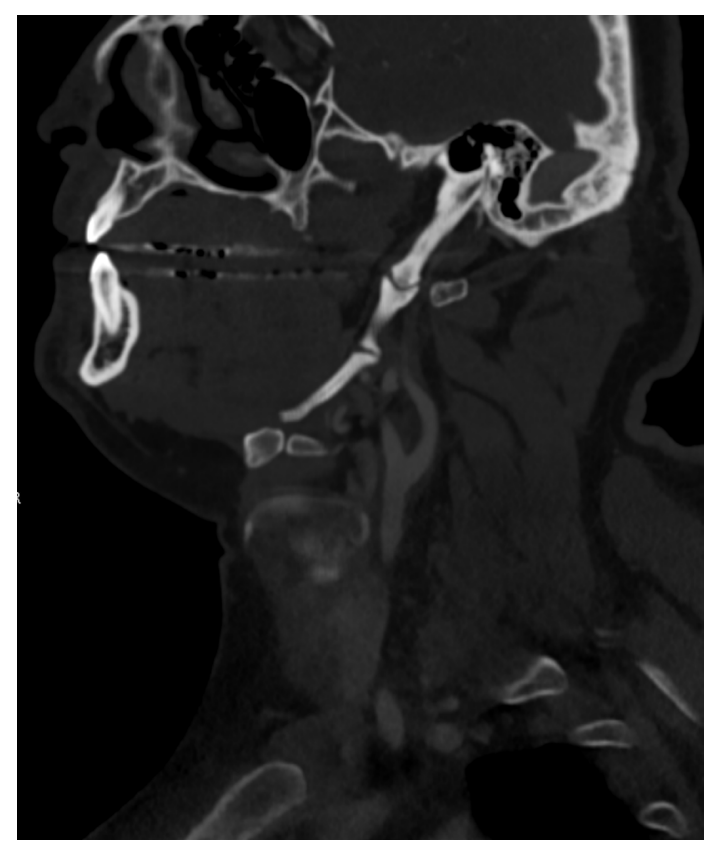

Figure 1 Sagittal CT depicting an elongated left styloid process.

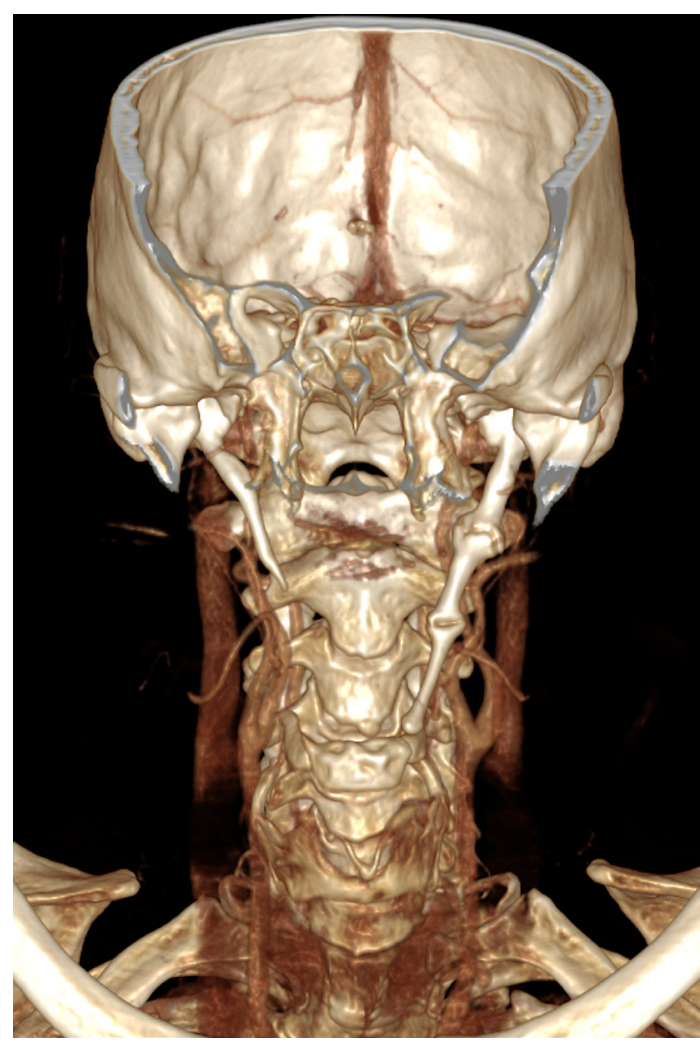

Figure 2 3-dimensional volume rendering of the CT images demonstrating the elongated left styloid process.

III elongated styloid). ${ }^{1}$ Recovery was unremarkable and the patient's symptoms resolved.

Eagle syndrome is the symptomatic elongation of the styloid process or calcification of the stylohyoid ligament. The length of the styloid process varies, however $30 \mathrm{~mm}$ is thought to be the upper limit of normal. $^{2}$

Several theories for Eagle syndrome have been proposed: (1) surgical trauma or local chronic irritation causing reactive ossifying hyperplasia within the stylohyoid complex; (2) reactive metaplasia secondary to the healing response to trauma and (3) normal anatomical variance.

Eagle syndrome may present with the classic features of facial/oropharyngeal pain exacerbated by head movement, globus sensation, dysphagia and otalgia. However, carotid artery and jugular vein variants have been described. ${ }^{4}$ The carotid variant results from the elongated styloid impinging the carotid artery causing carotid dissection, transient ischaemic attacks or impairment of sympathetic innervation. ${ }^{4}$ The jugular vein variant is associated with headache and dizziness, probably due to reduced cerebral venous 
flow. Furthermore, the jugular variant has been reported to be associated with idiopathic intracranial hypertension and perimesencephalic subarachnoid haemorrhage, both potentially a result of intracranial venous hypertension secondary to jugular impingement. ${ }^{45}$

The variation in presentation combined with the low incidence makes Eagle syndrome a diagnostic challenge. The differential diagnosis includes glossopharyngeal or sphenopalatine neuralgia, temporal arteritis, migraine, temporomandibular joint dysfunction, impacted molar teeth and myofascial pain dysfunction.

\section{Learning points}

- Oro-facial and neck pain has a wide differential diagnosis and the possibility of Eagle syndrome should be considered.

- Careful palpation of the tonsillar fossa may reveal a bony hard swelling and reproduce the symptoms.

- Arterial and venous narrowing should be investigated in cases of Eagle syndrome.

- Panoramic or cross-sectional imaging will confirm the diagnosis and aid surgical planning.
Diagnosis is based on clinical suspicion and is confirmed by imaging. Treatment can be surgical or non-surgical. Non-surgical options include anti-inflammatory medications and local anaesthetic injections into the tonsillar fossa. Surgical treatment requires styloidectomy which may be via an intra-oral or transcervical approach.

Contributors $A G$ and $A S$ were involved with writing the report. BA reconstructed the $\mathrm{CT}$ images and $\mathrm{AC}$ edited the manuscipt.

Competing interests None declared.

Patient consent for publication Obtained.

Provenance and peer review Not commissioned; externally peer reviewed.

\section{REFERENCES}

1 Langlais RP, Miles DA, Van Dis ML. Elongated and mineralized stylohyoid ligament complex: a proposed classification and report of a case of Eagle's syndrome. Oral Surg Oral Med Oral Pathol 1986;61:527-32.

2 Kaufman SM, Elzay RP, Irish EF, et al. Radiologic and clinical study. Arch Otolarngol 1970;91:63-460.

3 Politi M, Toro C, Tenani G. A rare cause for cervical pain: Eagle's syndrome. Int J Dent 2009:2009:781297.

4 Zamboni P, Scerrati A, Menegatti E, et al. The Eagle jugular syndrome. BMC Neurol 2019;19:333.

5 Higgins JN, Garnett MR, Pickard JD, et al. An evaluation of Styloidectomy as an adjunct or alternative to jugular stenting in idiopathic intracranial hypertension and disturbances of cranial venous outflow. J Neurol Surg B Skull Base 2017;78:158-63.

Copyright 2020 BMJ Publishing Group. All rights reserved. For permission to reuse any of this content visit

https://www.bmj.com/company/products-services/rights-and-licensing/permissions/

BMJ Case Report Fellows may re-use this article for personal use and teaching without any further permission.

Become a Fellow of BMJ Case Reports today and you can:

- Submit as many cases as you like

- Enjoy fast sympathetic peer review and rapid publication of accepted articles

- Access all the published articles

- Re-use any of the published material for personal use and teaching without further permission

Customer Service

If you have any further queries about your subscription, please contact our customer services team on +44 (0) 2071111105 or via email at support@bmj.com.

Visit casereports.bmj.com for more articles like this and to become a Fellow 